Editorial

\title{
Geriatric physiotherapy in Bangladesh: scope and prospect
}

Volume 7 Issue 6 - 2017

\section{Editorial}

Physiotherapy is a specialized branch of medical science. Physiotherapy started in Bangladesh around liberation war to rehabilitate injured freedom fighters. Gradually this profession spreads up in the field of orthopedics, neurology, rheumatology, chest condition, pediatric, sports science, burn \& plastic surgery, disability even gynecology. Recently a new dimension has been added where physiotherapists can work that is gerontology/geriatric care. Geriatric physical therapy is also considered as a medical specialty in 1989. Geriatric people are increasing in Bangladesh due to increase of life span. The average life span is now around 70 years and geriatric population contribute $7 \%$ of total population. This rapidly increasing population is a new and important group in terms of social and health policy in the country. Our constitution also gave priority on these population. Evidence suggests more than $95 \%$ of the elderly people reported experiencing health problems and most reported multiple health problems. More health problems were reported by women compared to men and in the rural region compared to the urban. Musculoskeletal problem among aged people is very common due to faulty posture, degeneration process as well as lack of care. Our day to day practice we observe that low back pain, osteoarthritic knee, muscle tingling \& burning sensation are very common among these large population. But there is no Govt run geriatric friendly hospital yet. Physiotherapy can help and promote senior citizen to retain and restore their independence, whether they are managing a long-term illness or just want to improve their general health and mobility. We know falling is a frequent tendency of elderly people. So flexibility, strength and balance is so important to maintain the desired level of fitness and overcome the challenge. Loss of these functions could lead to a fall that could cause serious injury. Physical therapy helps improve these functions. Physiotherapists have great opportunity to deal musculoskeletal problems of this vulnerable group but application

\author{
AKM Majbah Uddin,' Md Monoarul Haque ${ }^{2}$ \\ 'Senior Physiotherapist, Pan Pacific Hospital, Training \& Research \\ Institute, Bangladesh \\ 2Publication Secretary, Bangladesh Physiotherapy Association, \\ Bangaldesh
}

Correspondence: Md Monoarul Haque, Publication Secretary, Bangladesh Physiotherapy Association, Bangaldesh, Email monoarmunna@yahoo.com

Received: January 07, 2017 | Published: April 13, 2017

of therapeutic technique may be different because of physiological changes due to ageing process. Bone density, joint configuration, muscle power, mental condition of geriatric people may be different from younger and adult one. More empathy and patience is needed to treat old people rather than sympathy. Need more large scale research on musculoskeletal problem of aged groups. Community based geriatric friendly physiotherapy \& rehabilitation center can be instituted. Policy maker and concern authority can think about this issue because one day we will enter this age group and no prosperity possible neglecting this bulk group of population.

\section{Acknowledgments}

None.

\section{Conflicts of interest}

None. 